http://jmscr.igmpublication.org/home/ ISSN (e)-2347-176x ISSN (p) 2455-0450 crossref DOI: https://dx.doi.org/10.18535/jmscr/v7i7.60

\title{
Prevalence of Transfusion Transmissible Infections among Blood Donors at a Tertiary Care Hospital at Dhaka, Bangladesh
}

Authors

\section{Dr Daanish Arefin Biswas ${ }^{1 *}$, Dr Farida Parvin ${ }^{2}$, Dr Bepasha Naznin ${ }^{3}$, Dr Ferdous Ara ${ }^{4}$, Dr Md. Ashraful Hoque ${ }^{5}$, Dr Irani Begum ${ }^{6}$, Dr Kamrul Islam Khan Emon ${ }^{7}$}

${ }^{1}$ Associate Professor, Dept. of Transfusion Medicine, Sir Salimullah Medical College, Bangladesh

${ }^{2}$ Assistant Professor, Dept. of Transfusion Medicine and Clinical Hematology, BIRDEM, Bangladesh

${ }^{3}$ Specialist Transfusion Medicine, Asgar Ali Hospital, Bangladesh

${ }^{4}$ Associate Professor, Dept. of Transfusion Medicine, National Institute of Neurosciences \& Hospital,

Dhaka, Bangladesh

${ }^{5}$ CMBT, MIS, DGHS, Bangladesh

${ }^{6,7}$ Medical officer, Dept. of Transfusion Medicine, Sir Salimullah Medical College, Bangladesh

\begin{abstract}
Background: Disease transmission can occurs easily by transfusion of blood and components therapy. So screening is mandatory for all donated blood units for five transfusion transmitted diseases. It is necessary to know the current trends in results of screening for TTI in Bangladesh.

Objective: The present study was executed to assess the prevalence of infectious disease markers among donors at the blood bank of a tertiary care center, Sir Salimullah Medical College \& Mitford Hospital at Dhaka.
\end{abstract}

Materials and Methods: The study was a three year (2016-2018) retrospective study. A total of 35,831 donors comprising of 32606(91\%) males and 3225(9\%) females were screened over 3 years. There are no paid donors, all are either voluntary or replacement donors. Data was accumulated and analyzed from blood bank records for all donors who were screened for various TTIs using respective immunological methods.

Results: Mean percentage of these infections per year was found to be Hepatitis B surface antigen (HBsAg) was $1.27 \%$, Hepatitis C virus (HCV) was $0.013 \%$, HIV was $0.0028 \%$, syphilis was $0.078 \%$ andmalarial parasite (MP) was $0.0028 \%$.The overall seroreactivity in present study significantly diminished through successive years.

Conclusions: The risk of transfusion transmissible infection (TTI) today is low but attention should be paid onmethods to ensure a safety blood supply. For that screening with a better selection of donors and use of sensitive screening tests including nucleic acid testing technology should be implemented.

Keywords: Transfusion transmitted infections, Blood Donors, Prevalence, HBV, HCV.

\section{Introduction}

Transfusion of blood and its components is life saving as wellas it has life threatening hazards. With every unit of blood there is a $1 \%$ chance of transfusion associated problems including transfusion transmitted diseases. ${ }^{1}$
Blood donation saves the lives of millions of people worldwide; however, the patients are at a potential risk of contracting transfusiontransmitted infections (TTIs), which in turn impose serious challenges to the medical providers for the availability of safe and affordable bloodproducts. ${ }^{2}$ 
The accurate figures of TTIs in our population are still unknown due to the lack of understanding, un-availability of screening tests, limited access to health facilities and the unavailability of surveillance systems. $^{3}$

Lots of known cases of post transfusion diseases that have been caused by Human immunodeficiency virus (HIV), Hepatitis B virus (HBV), Hepatitis C virus (HCV), Treponema Pallidum and Malaria parasites. Preventing the transmission of infectious diseases through blood transfusion in developing countries is difficult given that the resources required are not always available even when policies and strategies are in place. These strategies have been extremely effective but transmission of diseases still occurs, primarily because of the inability of the test to detect the disease in the pre seroconversion or 'window' phase of their infection, high cost of screening, a lack of funds and trained personnel, immunologically variant viruses, nonseroconverting chronic or immuno-silent carriers and inadvertent laboratory testing errors. Transfusion Transmitted Infections is still a major concern to patients, physicians and policy makers who wish to see a risk free blood supply. ${ }^{4}$

Pre-donation screening of blood donors for Transfusion Transmissible Infections (TTI) is the practice by which a prospective donor is tested for the presence of one or more of the TTI agents by a single rapid or quick method, and donation is deferred if the test is reactive for any of the TTI markers. ${ }^{5}$

The aim of the present study was to find out prevalence of transfusion transmitted infections (TTI) in voluntary and replacement donors in our hospital transfusion service setup. This study also aids in evaluating the safety of the collected donations.

\section{Materials and Methods}

The study was done among all donors from the year 2016 up to 2018. All donors who had been selected to donate blood after the prospective donor had passed the haemoglobin check and the main exclusion criteria for donation, were screened for five mandatory tests for transfusion transmitted infections namely Hepatitis B surface antigen (HBsAg), hepatitis $\mathrm{C}$ virus (HCV), HIV, syphilis, and malaria. Prevalence and trend of infectious disease markers was studied. The subjects included all replacement and voluntary blood donors. No professional donor was accepted. Written consent was taken from donors. Recommended exclusion criteria were: history of febrile or debilitating illness, weight loss, jaundice, hepatic or cardiovascular or pulmonary derangement, malignancy, epilepsy, bleeding diathesis, past blood transfusion, recent blood donation, consumption of prohibited drugs, surgical intervention, age under 18 or over 60 years, pregnancy or lactation.

Screening tests were done by rapid test kits. Samples were found as reactive was rested for confirmation. All records were collected from blood bank records maintained as per Transfusion Medicine Department at SSMC \& Mitford Hospital.

\section{Results}

A total of 35,831 donors donated blood over 3 years. The total number of donors who were found positive for transfusion transmissible infections (TTIs) was 491/35,831(1.37\%) where males were dominant cohort. The male: female (M:F) ratio among the infected donor was15.36:1(94\% \& $6 \%$ ). (Figure 1) Altogether the highest prevalence for TTI was observed in the 18-30 years age group $(80 \%)$ followed by the $31-45$ years $(18 \%)$ and $2 \%$ in the 46-60years age group (Figure 2).In this study the seropositivity for various TTIs was found to be 456/491 (93\%) for HBsAg, 5/491 for HCV (1\%),1/491 (0.2\%) for HIV, 28/491 (5.7\%) for syphilis and $1 / 491(0.2 \%)$ for malarial parasite (MP).(Figure 3) The mean percentage of these infections per year was found to be $1.27 \%$, $0.013 \%, 0.0028 \%, 0.078 \%$ and $0.0028 \%$ for HBsAg, HCV,HIV, syphilis, and Malarial parasite respectively (Table 1 ). 


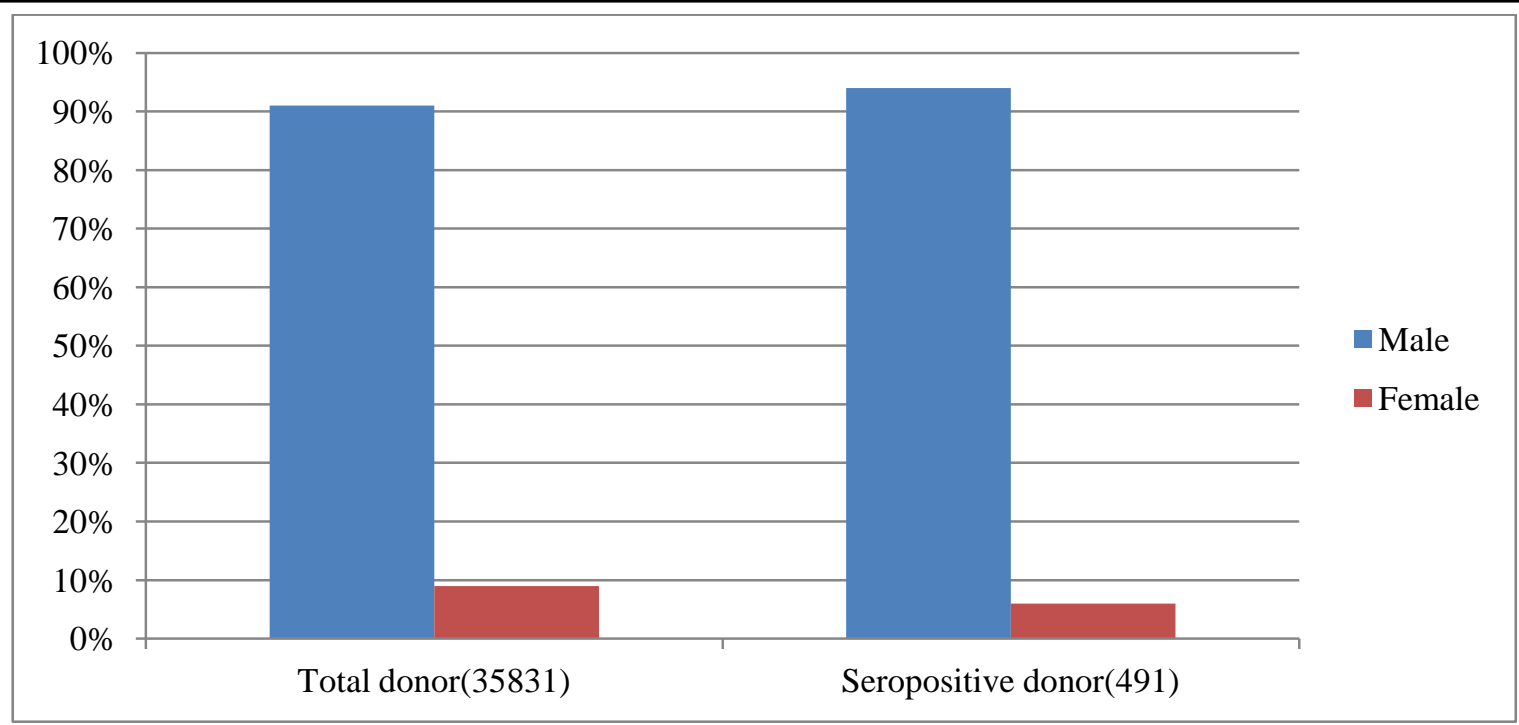

Figure 1: Sex distribution among blood donors and seropositive donors.

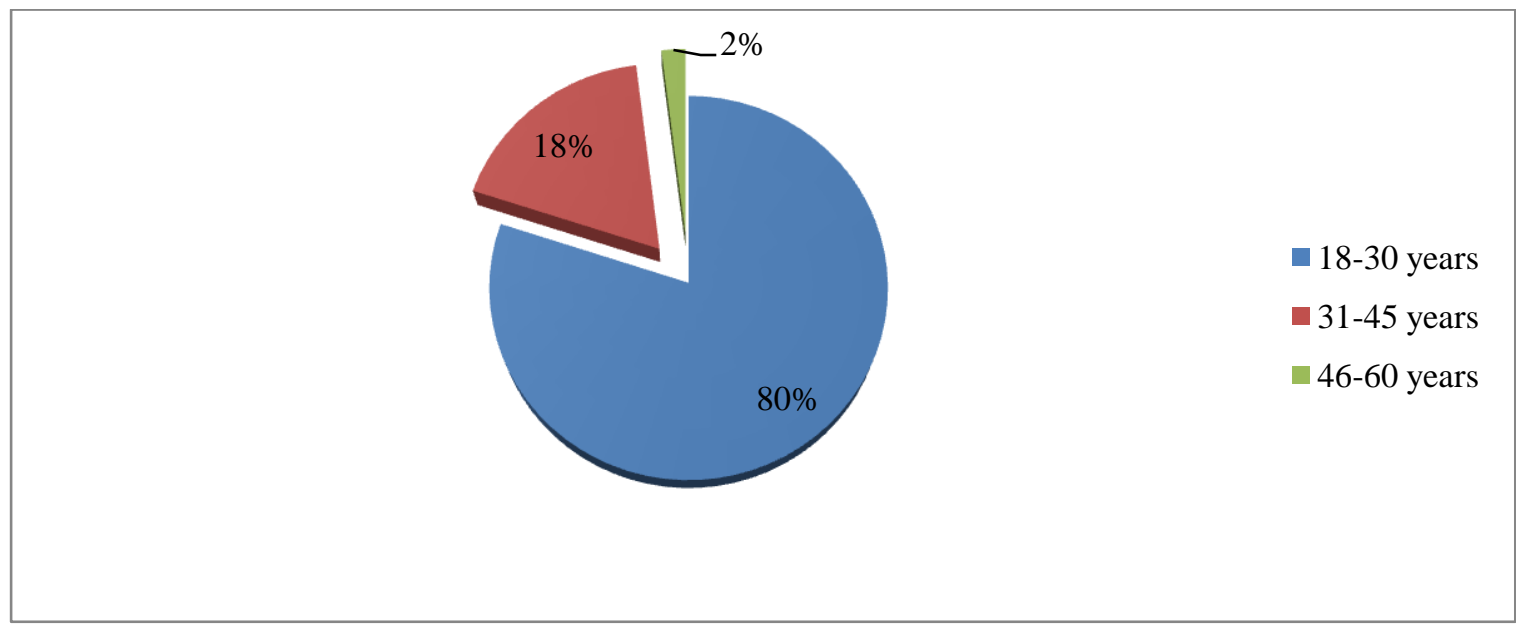

Figure 2: Age distribution among seropositive donors.

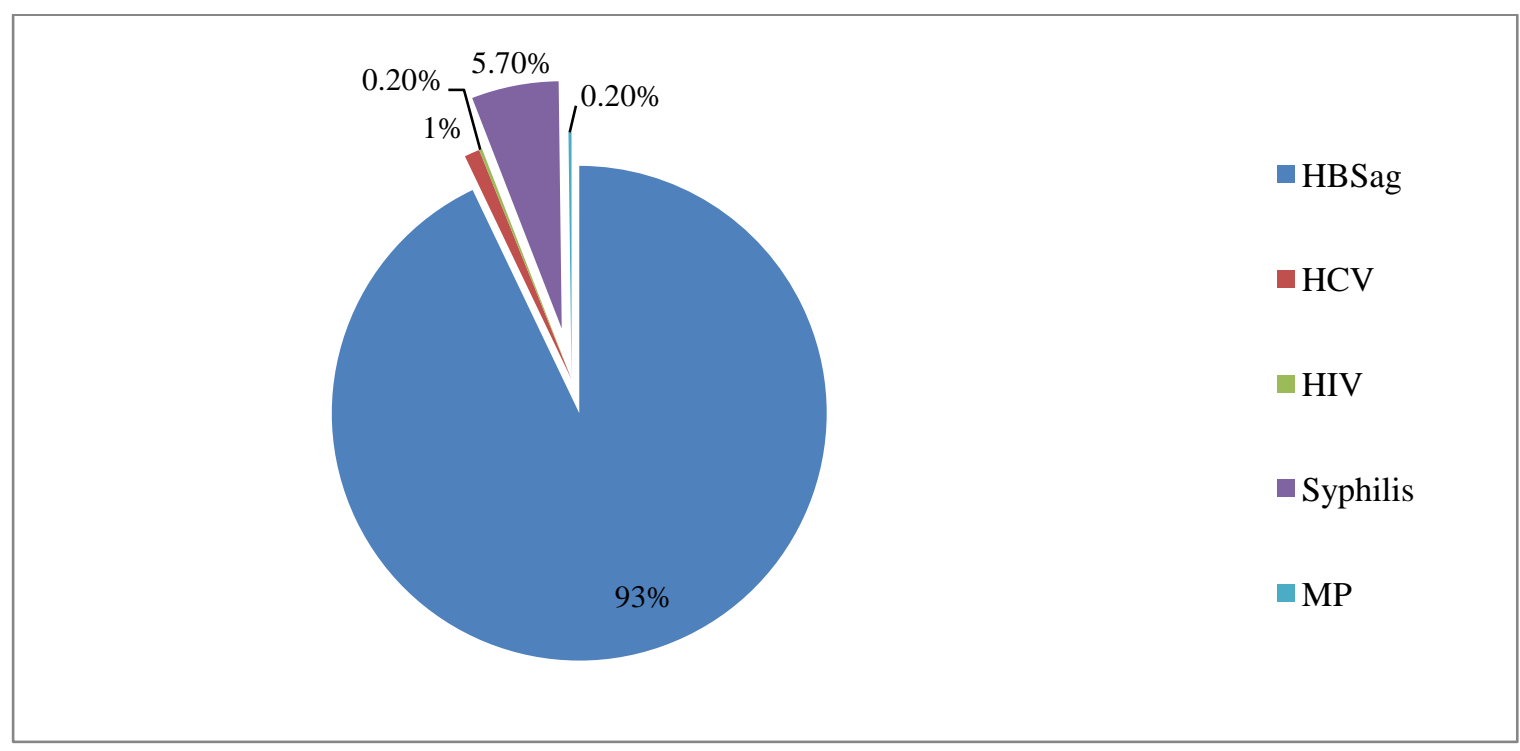

Figure 3: Prevalence of various TTIs as a whole during three years period. 


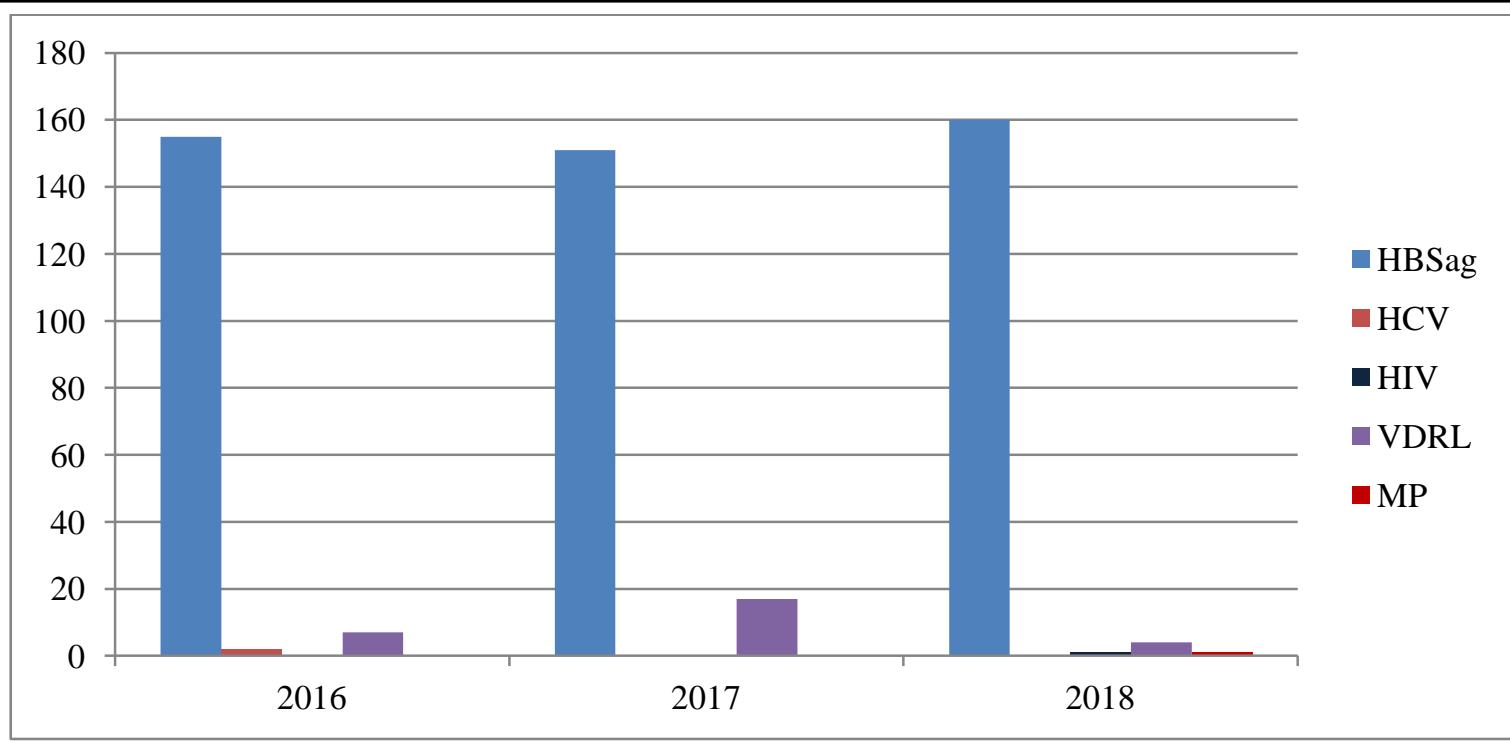

Figure 4: Seropositive donors in 3 successive years.

Table 1: Prevalence of TTIs from 2016 to 2018 among blood donors

\begin{tabular}{|c|c|c|c|c|c|c|c|c|c|c|}
\hline \multirow{3}{*}{ Disease } & \multirow{2}{*}{$\begin{array}{c}\text { Year } \\
\text { Donor }\end{array}$} & \multicolumn{2}{|c|}{2016} & \multicolumn{2}{|c|}{2017} & \multicolumn{2}{|c|}{2018} & \multicolumn{2}{|c|}{ Total } & \multirow{3}{*}{$\begin{array}{l}\text { Percentage } \\
\text { among } \\
\text { reactive TTI }\end{array}$} \\
\hline & & \multicolumn{2}{|c|}{9690} & \multicolumn{2}{|c|}{11905} & \multicolumn{2}{|c|}{14236} & \multicolumn{2}{|c|}{33831} & \\
\hline & & $\mathrm{N}$ & $\%$ & $\mathrm{~N}$ & $\%$ & $\mathrm{~N}$ & $\%$ & $\mathrm{~N}$ & $\%$ & \\
\hline $\mathrm{HBsAg}$ & & 155 & 1.6 & 151 & 1.27 & 150 & 1.054 & 456 & 1.2726 & 92.872 \\
\hline $\mathrm{HCV}$ & & 2 & 0.02 & 0 & 0 & 3 & 0.021 & 5 & 0.014 & 1.0183 \\
\hline HIV & & 0 & 0 & 0 & 0 & 1 & 0.007 & 1 & 0.0028 & 0.2037 \\
\hline VDRL & & 7 & 0.07 & 17 & 0.143 & 4 & 0.028 & 28 & 0.0781 & 5.7026 \\
\hline MP & & 0 & 0 & 0 & 0 & 1 & 0.007 & 1 & 0.0028 & 0.2037 \\
\hline Total & & 164 & 1.692 & 168 & 1.411 & 159 & 1.12 & 491 & 1.3703 & 100 \\
\hline
\end{tabular}

\section{Discussion}

Transfusion is a life-saving integral remedy in current medical practices, but also carries contemporary risk of transmitting dreadful TTIs like hepatitis B and C, HIV, Syphilis and less commonly to malaria, toxoplasmosis, brucellosis, other viral infections. ${ }^{6}$

In the whole world, HBsAg (Hepatitis B surface antigen) prevalence varies between 0.1 and $11.7 \%{ }^{7}$ Seroprevalence of HBsAg in various other Indian studies has been shown to range between 1.86 and $4 \%{ }^{8,9}$ Seroprevalence of HBsAg in various studies in Pakistan has been shown to range between 1.55 and $8.4 \%^{10,11}$ In the present study, the prevalence of TTIs was $1.37 \%$ whereas HBsAg was $1.27 \%$ which is $93 \%$ of all donors reactive for TTIs(Table1). The prevalence of HBsAg in a study in Khulna Medical College
Hospital, Khulna was $1.39 \%^{12}$. In another study in Sir Salimullah Medical College, Dhaka the prevalence was $2.19 \% .{ }^{13}$ The similarity among results seems to be due to nearly identical socioeconomic condition among these regions.

Universally around 3\% people are infected with $\mathrm{HCV} .{ }^{14}$ Accordingly, worldwide $0.4-19.2 \%$ blood donors test positively for $\mathrm{HCV} \cdot{ }^{15,16,17}$ In the present study the prevalence of sero-positivity for anti-HCV was $0.013 \%$ which is also low comparing theprevious findings. The prevalence of anti-HCV in a study by Ahmed et $\mathrm{al}^{12}$ was $0.024 \%$.In another study ${ }^{13}$ at Sir Salimullah Medical College, Dhaka the prevalence was $0.25 \%$. Extremely low anti-HCV prevalence $0 \%$ has been reported among the blood donors is UK and Scandinavia. ${ }^{14}$ The highest prevalence $(28 \%)$ has been reported in Egypt $^{18}$. Indian studies ${ }^{8,9}$ 
indicate that sero-prevalence of $\mathrm{HCV}$ ranges between 0.4 and $1.1 \%$. Several studies in Pakistan showed that the sero-prevalence of $\mathrm{HCV}$ rangesbetween 0.07 and $4.9 \% .^{10,11}$ The possible explanation for variation in this results across studies might be due to increased awareness of not taking blood from professional donors along with differences in socio-cultural practices.

In this study it has been found that the seroprevalence of HIV reactivity was $0.0028 \%$ which is very similar to Ahmed et $\mathrm{al}^{12}$, Saha et $\mathrm{al}^{13}$ and Karim et $\mathrm{al}^{19}$ in Bangladesh. The HIV seroprevalence in Indian scenario ${ }^{20,21}$ has been reported between 0.2 and $1 \%$. Interestingly Pakistan has reported no transfusion transmitted HIV infection ${ }^{10,11}$ along with one study from Bangladesh $^{22}$. In the present study, the VDRL was positive in $0.078 \%$ donor blood. The prevalence of VDRL in a study ${ }^{12}$ in Khulna Medical College Hospital, Khulna was $0.00 \%$. In another study ${ }^{13}$ in Sir Salimullah Medical College, Dhaka the prevalence was $0.17 \%$. In this study seroprevalence of Malaria among donors was $0.0028 \%$. A study from Bangladesh ${ }^{22}$ has showed $0.00 \%$ and another study by Karim $^{19} 0.010 \%$ malaria present among their donors whereas a study from India $^{21}$ showed a prevalence of $0.107 \%$.Very low incidence of HIV, Malaria and Syphilis in our study may reflect knowledgeable blood donors with better understanding of blood safety, effective outcome due to avoidance of paid donors and also better sensitive screening tests used countrywide during last few years reducing potentially dangerous donors.

The overall seroprevalence of five TTIs among the studied donors figured out as $1.37 \%$ with a significant dwindling trend over successive years as $1.69 \%$ in $2016,1.41 \%$ in 2017 and $1.12 \%$ in 2018.(Figure $4 \&$ Table1). Previous studies from Bangladesh showed prevalence of $1.42 \%{ }^{11}$ and $1.45 \%{ }^{22}$. The results are identical probably due to demographic similarity. Male donors are more seropositive (94\%). A study from Ethiopia showed nearly equal $\mathrm{M}: \mathrm{F}=8.9 \%: 7.1 \% .{ }^{23}$ Presence of more male directed blood donors than females is most probable cause for such a high ration of ours. Highest prevalence of TTI were seen among 18-30 years age group (80\%) in our study with $20 \%$ in greater than 30 years of age. This findings is much high than Ethiopian study showed $23.6 \%$ TTI infected below age 30 years and $43.9 \%$ among age greater than $30 .{ }^{23}$ Presence of more young donors in our blood bank than aged one is most probable cause for such high gap found.

\section{Conclusion}

Transfusion transmitted infections is an alarming thing that affect blood donors in Bangladesh, though with a significant downhill tendency in overall seroprevalence through the years, attention should be paid toward the prevention of hepatitis $\mathrm{B}$ virus. Donors who are between 18 and 30 years, usually significantly associated with TTIs as good as the voluntary and replacement donors do. Risk behavior based donor selection with proper donor education and better screening tests will provide more safe blood free from TTIs. Strict selections of blood donors are highly recommended.

\section{Conflict of interest}

All authors declare that they have no competing interest.

\section{Limitations of the study}

The major limitation of the study was selection of blood donors from only a single center.

\section{Acknowledgements}

All authors acknowledge all the staff members of Department of Transfusion Medicine of Sir Salimullah Medical College Mitford Hospital and the blood donors attending the hospital.

\section{References}

1. Widman FK (ed) (1985) Technical manual. American Association of Blood Banks, Arlington, pp 325-344.

2. Arshad A, Borhany M, Anwar N, et al. Prevalence of transfusion transmissible infections in blood donors of Pakistan. BMC Hematol. 2016;16:27. 
3. Attaullah S, Khan S, Khan J. Trend of transfusion transmitted infections frequency in blood donors: provide a road map for its prevention and control. J Transf Med. 2012;10(1):1

4. Shittu AO, Olawumi HO, Adewuyi JO. Pre-donation screening of blood for transfusion transmissible infections: the gains and the pains - experience at a resource limited blood bank. Ghana Med J. 2014;48(3):158-162.

5. Shittu AO, Olawumi HO, Adewuyi JO. Pre-donation screening of blood for transfusion transmissible infections: the gains and the pains - experience at a resource limited blood bank. Ghana Med J. 2014;48(3):158-162.

6. Mollison P.L., Engelfriet C.P., Contreras M. Infectious agents transmitted by transfusion. In: Klein H., Anstee D., editors. Mollison's Blood Transfusion in Clinical Medicine. 11th ed. Blackwell Publishing; Massachusetts: 2005. pp. 701702.

7. Koshy J.M., Manoharan A., John M., Kaur R., Kaur P. Epidemiological profile of seropositive blood donors at a tertiary care hospital in North India. CHRISMED J Health Res. 2014;1:91-94.

8. Chandrasekaran S, Palaniappan N, Krishnan V, Mohan G, Chandrasekaran N. Relative prevalence of hepatitis $\mathrm{B}$ viral markers and hepatitis $\mathrm{C}$ virus antibodies (anti-HCV) in Madurai, South India. Indian Journal of Medical Sciences 2000; 547:270-73.

9. Srikrishna A, Sitalakshmi S, Damodar P. How safe are our safe donors? Indian Journal of Pathology and Microbiology 1999; 424:411-16.

10. Khan MA, Rehman A, Ashraf M, Ali A, Ditta A. Prevalence of $\mathrm{HBV}, \mathrm{HCV}$ and HIV in blood donors at Liaquatpur. Professional Med J. 2006; 13:23-26.
11. Mahmood MA, Khawar S, Anjum AH, et al. Prevalence of Hepatitis B, C and HIV infection in blood donors of Multan region. Ann King Edward Med Coll. 2004; 10:459-61.

12. Ahmed MU, Begum HA, Hossain T, Chakraborty P. Prevalence of Transfusion Transmitted Infection among Blood Donors. JAFMC Bangladesh. 2009;5(1):48.

13. Saha SK, Banik RK, Saha MR, Habibullah MM, Mahtab MA. Prevalence of Transfusion Transmitted Infection in Healthy Blood Donors in Sir Salimullah Medical College. Euroasian Journal of Hepato-Gastroenterology,2011;1(2):68-70.

14. WHO Global surveillance and control of hepatitis C. Report of a WHO consultation organized in collaboration with the Viral Hepatitis Prevention Board, Antwerp, Belgium. J Viral Hepat. 1999;6:35-47.

15. Datta S. An overview of molecular epidemiology of hepatitis B virus (HBV) in India. Virol J. 2008;5:156.

16. Panda M., Kar K. HIV, hepatitis B and C infection status of the blood donors in a blood bank of a tertiary health care centre of Orissa. Indian $\mathbf{J}$ Public Health. 2008;52:43-44.

17. Sood G., Chauhan A., Sehgal S., Agnihotri S., Dilawari J.B. Antibodies to hepatitis C virus in blood donors. Indian $\mathrm{J}$ Gastroenterol. 1992;11:44.

18. Armstrong G, Alter M, McQuillang, et al. The past incidence of hepatitis $\mathrm{C}$ virus infection implication for the future burden of chronic liver disease in United States. Hematol 2000; 31:777-82.

19. Karim,S., Hoque, E and Hoque, M.M. (2016). Transfusion Transmissible Diseases Among Healthy Blood Donors Attended at Transfusion Medicine Department of DMCH in 2014.Anwar Khan modern medical college journal; 7(1): 11-13. 
20. Garg S, Mathur DR, Garg DK. Comparison of seropositivity of HIV, $\mathrm{HBV}, \mathrm{HCV}$ and syphilis in replacement and voluntary blood donors in Western India. Indian Journal of Pathology and Microbiology 2001; 444:409-12.

21. Paramjit K, Basu S. Transfusiontransmitted infections: Existing and emerging pathogens. Journal of Post Graduate Medicine 2005; 51:146-51.

22. Ara F, Nasreen Z, Islam MA, Yusuf MA, Hassan MS, Sonia SF. Frequency of Transfusion Transmitted Infection Among Blood Donors at Specialized Tertiary Care Hospital in Bangladesh, J Natl Inst Neurosci Bangladesh 2015;1(1): 12-14.

23. Bisetegen FS, Bekele FB, Ageru TA, Wada FW. Transfusion-transmissible infections among voluntary blood donors at Wolaita Sodo university teaching referral hospital, South Ethiopia. Can J Infect Dis Med Microbiol. 2016;2016:8254343. 